\title{
Multidrug- and extensively drug-resistant tuberculosis: a persistent problem in the European Union European Union and European Economic Area
}

C Ködmön (csaba.kodmon@ecdc.europa.eu) ${ }^{1}$, V Hollo $^{1}$, E Huitric $^{2}$, A Amato-Gauci $^{3}$ D Manissero²

1. Surveillance Unit, Tuberculosis Programme, European Centre for Disease Prevention and Control, Stockholm, Sweden

2. Scientific Advice Unit, Tuberculosis Programme, European Centre for Disease Prevention and Control, Stockholm, Sweden

3. Surveillance Unit, European Centre for Disease Prevention and Control, Stockholm, Sweden

Citation style for this article:

Citation style for this article: Ködmön C, Hollo V, Huitric E, Amato-Gauci A, Manissero D. Multidrug- and extensively drug-resistant tuberculosis: a persistent problem in the European Union European Union and European Economic Area. Euro Surveill. 2010;15(11): pii=19519. Available online: http://www.eurosurveillance. org/ViewArticle.aspx?Articleld $=19519$

This article has been published on 18 March 2010

Since 2008, the European Centre for Disease Prevention and Control has been collecting data from the European Union (EU) and European Economic Area (EEA) on resistance to first- and second-line drugs against tuberculosis (TB). In 2008, the proportion of multidrug-resistant tuberculosis (MDR TB) was $6.0 \%$ of the total case load for 25 countries reporting data. Extensively drug-resistant (XDR TB) reporting has increased since 2007 and was observed in $7.3 \%$ of the MDR TB cases in 13 reporting countries. MDR TB remains a threat and XDR TB is now established within the EU/EEA borders.

\section{Background}

Tuberculosis (TB) is among the leading causes of death due to a single pathogen worldwide. The World Health Organization (WHO) estimates that $32 \%$ of the world population is infected with Mycobacterium tuberculosis, the causative agent of tuberculosis [1], with 9.2 million new TB cases and 1.7 million deaths from TB reported in 2007 [2]. Drug resistance to isoniazid and rifampicin (the definition for multidrug-resistant (MDR) TB), the two most potent first-line antimicrobial drugs for the treatment of $\mathrm{TB}$, is a persisting global problem with surveillance data indicating increasing trends in several countries [3-7]. In 2007, the WHO reported the highest rates of MDR TB ever recorded, with up to $22 \%$ of new TB cases being resistant to both isoniazid and rifampicin in some areas of the former Soviet Union [2]. The increases in prevalence and incidence of MDR TB are caused by concurrent factors such as inadequate treatment regimens, poor case holding, suboptimal drug quality and transmission of resistant strains [8]. In recent years, public health awareness about MDR TB has been reinforced by the occurrence of extensively drug-resistant (XDR) TB outbreaks associated with human immunodeficiency virus (HIV) infections, particularly in South Africa [9,10]. XDR TB strains are defined as strains resistant to isoniazid and rifampicin (i.e. MDR) as well as to a fluoroquinolone and to one or more of the following injectable drugs: amikacin, capreomycin, or kanamycin).

In Europe, the prevalence of MDR TB is high, particularly in some areas [4], and past surveillance reports have highlighted that MDR TB and XDR TB are a threat to TB control and elimination, also within the borders of the Member States of the European Union (EU) and European Economic Area (EEA) [11,12]. We therefore aimed at analysing the most recent data for the EU and EEA to describe the current MDR/XDR TB situation in this region.

\section{Methods}

Surveillance of drug resistance, based on annual casebased reporting of drug susceptibility testing (DST) results, has been ongoing in Europe since 1998 through the EURO-TB network and has included annual reporting of MDR TB cases [13]. Since 2008, the European Centre for Disease Prevention and Control (ECDC) and the WHO Regional Office for Europe have jointly been conducting TB surveillance for Europe. Data for the EU and EEA countries are reported to the ECDC through the European surveillance system, TESSy.

Since the reporting year 1998, DST results from initial M. tuberculosis isolates have been collected for isoniazid, rifampicin, ethambutol and streptomycin. Since 2009, DST data for MDR TB cases on fluoroquinolones (ciprofloxacin, ofloxacin) and second-line injectable anti-TB drugs (amikacin, kanamycin and capreomycin) have been collected and reports have included retrospective data from 2007 and 2008. In this study, data was extracted from TESSy for EU and EEA countries reporting resistance to first-line drugs for the reporting year 2008. For the reporting years 2007 and 2008, data was extracted for EU and EEA countries reporting resistance to second-line drugs for MDR TB cases. 


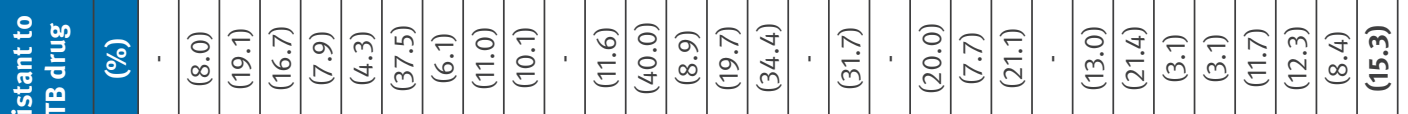

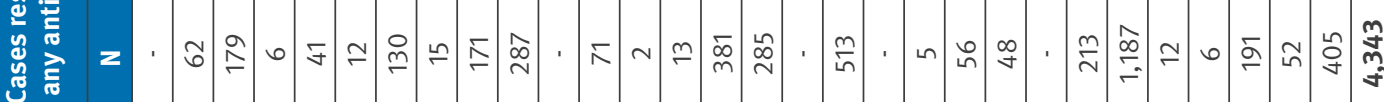

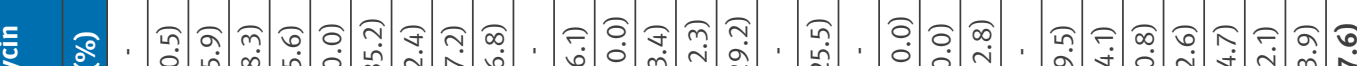

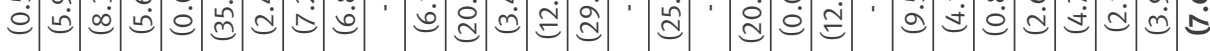

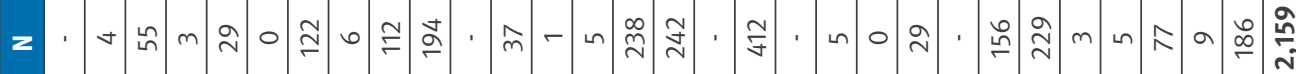

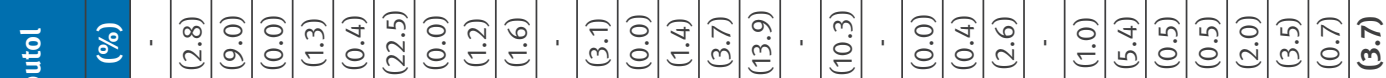

㟥言

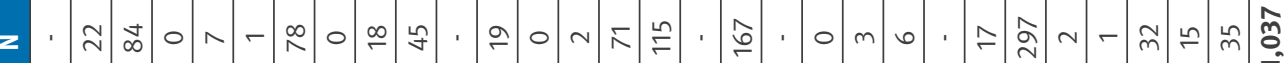

들 을

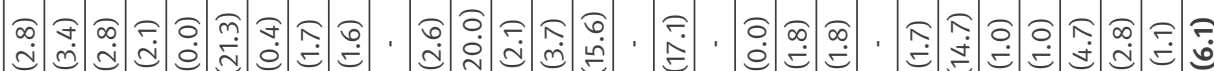

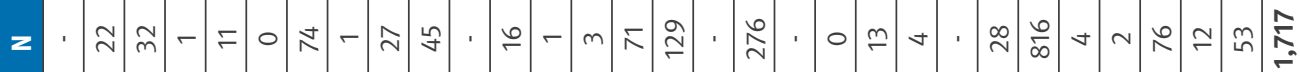

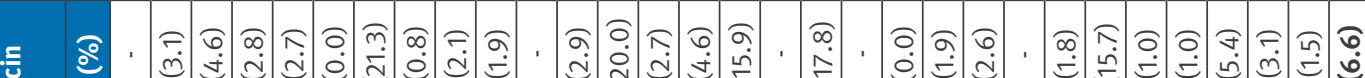

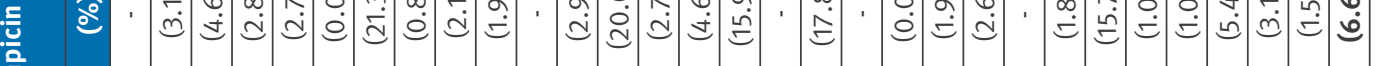

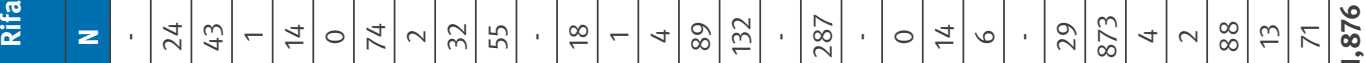

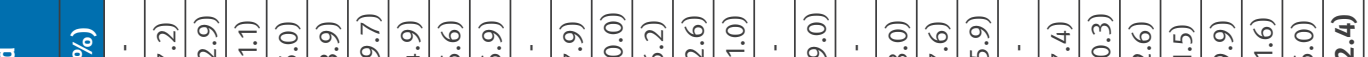
芒

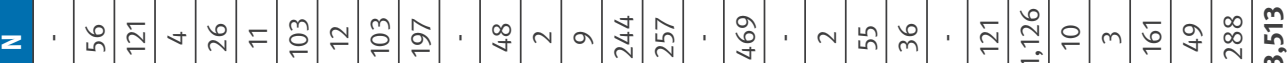

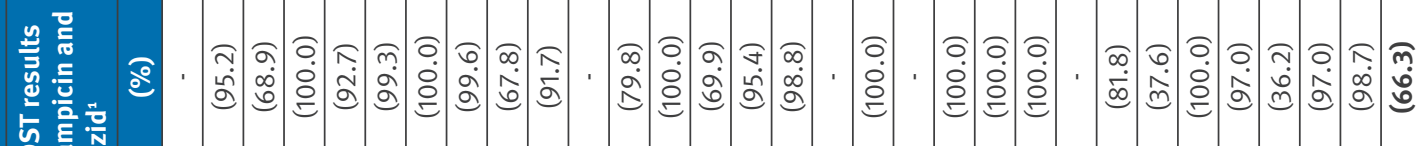

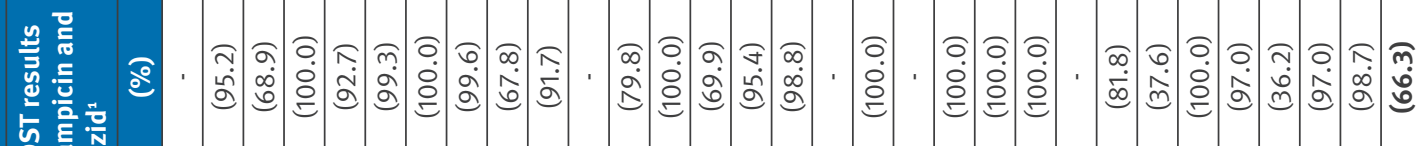

就

s.

$z$

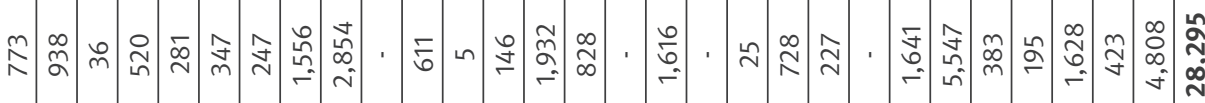

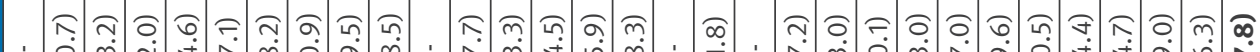

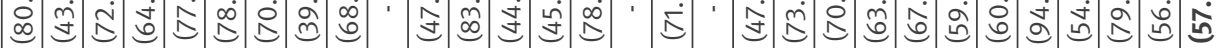

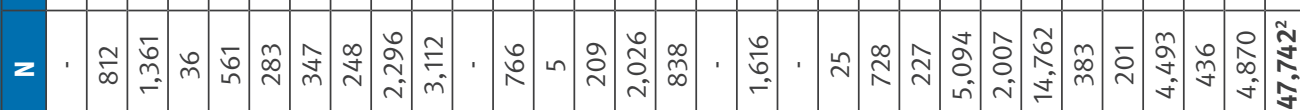


The total number of cases, the total number of culturepositive cases and the total number of cases with DST results (sensitive or resistant to at least isoniazid and rifampicin) were extracted to assess the interpretability of DST data.

The proportions of drug-resistant cases were calculated using the total number of cases with available DST results for at least isoniazid and rifampicin as a denominator; if these cases also included results for ethambutol and streptomycin, DST results for these antibiotics were also analysed. Cases of MDR TB were defined as cases resistant to at least isoniazid and rifampicin. In order to analyse findings on MDR
TB among new and retreatment cases, MDR TB data among reported cases were stratified by history of previous treatment. New cases were defined as cases who had never previously received drug treatment for active $T B$, or who had received anti-TB drugs for less than one month. Retreatment cases were defined as cases who had received treatment with anti-TB drugs (excluding preventive therapy) for at least one month.

Among MDR TB cases reported for 2007 and 2008, those with positive DST results for any of the reportable fluoroquinolones as well as to at least one of the reportable injectables were classified as XDR TB cases. The standard international definition for XDR TB was

TABLE 2

Multidrug-resistant cases by previous history of tuberculosis treatment in the EU/EEA, 2008

\begin{tabular}{|c|c|c|c|c|c|c|}
\hline \multirow[b]{2}{*}{ Country } & \multicolumn{2}{|c|}{ New } & \multicolumn{2}{|c|}{ Retreatment } & \multicolumn{2}{|c|}{ Treatment history unknown } \\
\hline & $\begin{array}{l}\text { Cases with DST } \\
\text { results }\end{array}$ & \begin{tabular}{|c|} 
Multidrug-resistant \\
N (\%)
\end{tabular} & $\begin{array}{l}\text { Cases with DST } \\
\text { results }\end{array}$ & $\begin{array}{c}\text { Multidrug-resistant } \\
\text { N (\%) }\end{array}$ & $\begin{array}{l}\text { Cases with DST } \\
\text { results }\end{array}$ & $\begin{array}{c}\text { Multidrug- } \\
\text { resistant }\end{array}$ \\
\hline Austria & - & $\cdots$ & - & $-\cdot$ & - & $\cdots$ \\
\hline Belgium ${ }^{1}$ & 621 & $14(2.3)$ & 57 & $7(12.3)$ & 95 & $1(1.1)$ \\
\hline Bulgaria & 833 & $14(1.7)$ & 105 & $18(17.1)$ & 0 & $0-$ \\
\hline Cyprus & 11 & $0(0.0)$ & 3 & $1(33.3)$ & 22 & $0(0.0)$ \\
\hline Czech Republic & 483 & $10(2.1)$ & 37 & $1(2.7)$ & 0 & $0-$ \\
\hline Denmark $^{1}$ & 253 & $0(0.0)$ & 28 & $0(0.0)$ & 0 & $0-$ \\
\hline Estonia & 272 & $42(15.4)$ & 75 & $32(42.7)$ & 0 & $0-$ \\
\hline Finland & 238 & $1(0.4)$ & 9 & $0(0.0)$ & 0 & $0-$ \\
\hline France & 1,313 & $16(1.2)$ & 104 & $10(9.6)$ & 139 & $1(0.7)$ \\
\hline Germany & 2,450 & $16(0.7)$ & 153 & $21(13.7)$ & 343 & $8(2.3)$ \\
\hline Greece & - & $\cdots$ & - & $\cdots$ & - & $\cdots$ \\
\hline Hungary & 509 & $8(1.6)$ & 97 & $6(6.2)$ & 5 & $2(40.0)$ \\
\hline Iceland & 4 & $1(25.0)$ & 0 & $0(0.0)$ & 1 & $0(0.0)$ \\
\hline Ireland $^{1}$ & 113 & $2(1.8)$ & 9 & $0(0.0)$ & 24 & $1(4.2)$ \\
\hline Italy & 1,018 & $27(2.7)$ & 165 & 24 (14.5) & 749 & $20(2.7)$ \\
\hline Latvia & 684 & $83(12.1)$ & 144 & 46 (31.9) & 0 & $0-$ \\
\hline Liechtenstein & - & $\cdots$ & - & $\cdots$ & - & $\cdots$ \\
\hline Lithuania & 1,259 & $113(9.0)$ & 356 & $162(45.5)$ & 1 & $1(100.0)$ \\
\hline Luxembourg & - & $\cdots$ & - & $\cdots$ & - & $\cdots$ \\
\hline Malta & 22 & $0(0.0)$ & 3 & $0(0.0)$ & 0 & $0-$ \\
\hline Netherlands & 696 & $11(1.6)$ & 23 & $2(8.7)$ & 9 & $0(0.0)$ \\
\hline Norway $^{1}$ & 174 & $1(0.6)$ & 20 & $2(10.0)$ & 33 & $1(3.0)$ \\
\hline Poland & - & $\cdots$ & - & $\cdots$ & - & $\cdots$ \\
\hline Portugal & 1,496 & $19(1.3)$ & 145 & $9(6.2)$ & 0 & $0-$ \\
\hline Romania & 3,025 & $130(4.3)$ & 2,522 & $686(27.2)$ & 0 & $0-$ \\
\hline Slovakia & 300 & $1(0.3)$ & 61 & $2(3.3)$ & 22 & $1(4.5)$ \\
\hline Slovenia & 183 & $1(0.5)$ & 12 & $1(8.3)$ & 0 & $0-$ \\
\hline Spain & 1,080 & $31(2.9)$ & 174 & $23(13.2)$ & 374 & $22(5.9)$ \\
\hline Sweden & 341 & $7(2.1)$ & 38 & $4(10.5)$ & 44 & $1(2.3)$ \\
\hline United Kingdom ${ }^{1}$ & 3,707 & $38(1.0)$ & 228 & $7(3.1)$ & 873 & $8(0.9)$ \\
\hline Total EU/EEA & 21,085 & $586(2.8)$ & 4,568 & $1,064(23.3)$ & 2,734 & $67(2.5)$ \\
\hline
\end{tabular}

DST: drug sensitivity testing; EEA: European Economic Area; EU: European Union; TB: tuberculosis.

- : not reported

1 Any resistance to isoniazid, rifampicin, ethambutol or streptomycin, expressed as a percentage of cases with available DST results at least to isoniasid and rifampicin. Testing for ethambutol and streptomycin not routine in all countries. 
therefore applied [14]. Changes in the prevalence of XDR TB among MDR TB cases between 2007 and 2008 were analysed.

\section{Findings}

In 2008, 47,742 culture-positive TB cases were reported by $27 \mathrm{EU}$ and EEA Member States. This represents $57.8 \%$ of the total TB case load $(82,611)$, with the percentage ranging from $36.2 \%$ to $100 \%$ among the reporting countries (Table 1 ). Data on resistance to first-line drugs in 2008 were available for 25 countries, representing a total of 28,295 cases $(66.3 \%$ of the total culture-positive cases, excluding culture-confirmed cases from Poland as DST data was not reported) (Table 1).

In 2008, the proportion of culture-positive TB cases resistant to any first-line anti-TB drug was $15.3 \%$ $(\mathrm{N}=4,343)$. The proportion of resistance to either isoniazid or rifampicin among culture-positive cases was $12.4 \%(\mathrm{~N}=3,513)$ and $6.6 \%(\mathrm{~N}=1,876)$, respectively (Table 1). The proportion of combined (new and retreatment) MDR TB cases in the 25 countries was $6.0 \%$, as shown in Table 1. The Baltic States (Latvia, Lithuania and Estonia) and Romania showed the highest proportions $(15.6 \%, 17.1 \% 21.3 \%$ and $14.7 \%$, respectively) of MDR TB cases (Table 1). The overall proportion of MDR TB among new cases was $2.8 \%$, ranging from $0 \%$ to $25 \%$, and was again highest in the Baltic States (9.0\%-15.4\%) and Iceland (25.0\%, one case). Among retreatment cases, the overall proportion of MDR cases was $23.2 \%$, with the highest proportions in the Baltic States (31.9\%-45.5\%), Cyprus (33.3\%, one case) and Romania (27.2\%) (Table 2).

Thirteen countries provided data on resistance to second-line drugs, allowing the identification of XDR TB cases for the reporting years 2007 and 2008. Among the total of 1,122 MDR TB cases (new and retreatment cases) reported by these 13 countries in 2007 , 68 were XDR TB cases, representing $6.1 \%$ of the total MDR TB burden. In 2008, 90 XDR TB cases were notified, with the proportion of XDR TB cases among MDR TB cases increasing to $7.3 \%$. Latvia and Romania had the highest number of XDR TB cases in 2008 (19 and 54 cases, respectively). In Estonia, a decline in the total number and proportion of XDR TB cases from 12 to nine cases (15.0\% to $12.2 \%)$ was observed compared to 2007 , while in Latvia had an increase in the number of reported XDR TB cases in 2008 relative to 2007 from six to 19 cases $(6.1 \%$ to $14.7 \%)$ (Table 3$)$.

\section{Conclusions}

The data highlight two important findings concerning the MDR/XDR TB situation in the EU/EEA Member States. First, it is evident that reporting completeness remains suboptimal in this region. In particular, the percentage of the total TB case load for which the drug resistance profile for at least isoniazid and rifampicin is known, remains low. The DST results were available for only $34.4 \%$ of the total notified cases $(28,295$ of 82,611 cases in 2008), reflecting a low culture positivity rate $(57.5 \%)$ and a low DST coverage $(66.4 \%$ of culturepositive cases). This represents not only a surveillance limitation, but it could also hamper the implementation of proper TB control practices such as infection control and case management.

Secondly, the data highlights the fact that MDR TB persists as a threat to the EU/EEA. This is underlined by four of the five WHO High Priority Countries within the EU/EEA (Estonia, Latvia, Lithuania and Romania) reporting proportions of combined MDR TB of well over $10 \%$ of the total case load [15]. The analysis of MDR

\section{TABLE 3}

Extensively drug-resistant tuberculosis cases in the EU/EEA, 2007-2008

\begin{tabular}{|c|c|c|c|c|c|c|}
\hline & Total MDR-TB & Total XDR-TB & $\begin{array}{c}\text { XDR/MDR } \\
\%\end{array}$ & Total MDR-TB & Total XDR-TB & $\begin{array}{c}\text { XDR/MDR } \\
\%\end{array}$ \\
\hline Belgium & 14 & 1 & (7.1) & 22 & 2 & $(9.1)$ \\
\hline Bulgaria & 76 & 0 & $(0.0)$ & 32 & 0 & $(0.0)$ \\
\hline Cyprus & 3 & 0 & $(0.0)$ & 1 & 0 & $(0.0)$ \\
\hline Czech Republic & 8 & 0 & $(0.0)$ & 11 & 1 & $(9.1)$ \\
\hline Estonia & 80 & 12 & $(15.0)$ & 74 & 9 & $(12.2)$ \\
\hline Iceland & 1 & 0 & $(0.0)$ & 1 & 0 & $(0.0)$ \\
\hline Latvia & 99 & 6 & $(6.1)$ & 129 & 19 & $(14.7)$ \\
\hline Norway & 3 & 1 & (33.3) & 4 & 0 & $(0.0)$ \\
\hline Romania & 701 & 47 & $(6.7)$ & 816 & 54 & $(6.6)$ \\
\hline Slovakia & 7 & 0 & $(0.0)$ & 4 & 0 & $(0.0)$ \\
\hline Spain & 59 & 0 & - & 76 & 3 & (3.9) \\
\hline Sweden & 15 & 1 & (6.7) & 12 & 1 & (8.3) \\
\hline United Kingdom & 56 & 0 & $(0.0)$ & 53 & 1 & (1.9) \\
\hline Total EU/EEA & 1,122 & 68 & (6.1) & 1,235 & 90 & (7.3) \\
\hline
\end{tabular}

MDR: multidrug-resistant; EEA: European Economic Area; EU: European Union; TB: tuberculosis; XDR: extensively drug-resistant. 
TB reporting can be used to indicate weaknesses in TB control programmes. The high proportion of MDR TB among new TB cases reported by certain countries could suggest suboptimal infection control, whilst the high percentage of MDR TB among retreatment cases (23.3\%) could suggest poor case holding and followup or suboptimal use of TB regimens during the past decade.

For the first time since the surveillance of anti-TB drugs has been performed at EU level, notification data on XDR TB is available through the joint surveillance system. Although the quality and completeness of second-line resistance data remains questionable, the numbers confirm that XDR TB is now established in the EU. The increase of $32.4 \%$ in reported XDR TB cases is difficult to interpret as this could well represent an improvement in DST coverage for second-line drugs, as opposed to representing a true increase in the prevalence of XDR TB.

The link and interdependence between TB surveillance, TB case management and control of drug-resistant TB is well reflected by these data. Improvement in the quality and completeness of MDR/XDR TB surveillance data is needed. This will be achieved by the countries' serious commitment to optimise TB control practices as well as improve TB case management, which in turn should reverse the of MDR/XDR TB trends observed in recent years.

\section{References}

1. Global tuberculosis control: surveillance, planning financing WHO report 2007. Geneva: World Health Organization; 2007.

2. Global tuberculosis control: epidemiology, strategy, financing: WHO report 2009. Geneva: World Health Organization; 2009. Available from: http://whqlibdoc.who.int/ publications/2009/9789241563802_eng.pdf

3. Zignol M, Hosseini MS, Wright A, Weezenbeek CL, Nunn P, Watt CJ, et al. Global incidence of multidrug-resistant tuberculosis. J Infect Dis. 2006;194(4):479-85.

4. Aziz MA, Wright A, Laszlo A, De Muynck A, Portaels F, Van Deun A, et al. Epidemiology of antituberculosis drug resistance (the global project on anti-tuberculosis drug resistance surveillance): an updated analysis. Lancet. 2006;368(9553):2142-54.

5. Espinal MA, Laszlo A, Simonsen L, Boulahbal F, Kim SJ, Reniero A, et al. Global trends in resistance to antituberculosis drugs. World Health Organization-International Union against Tuberculosis and Lung Disease Working Group on Anti-Tuberculosis Drug Resistance Surveillance. N Engl J Med. 2001;344(17):1294-303.

6. WHO launches new Stop TB strategy to fight the global tuberculosis epidemic. Indian J Med Sci. 2006;60(3):125-6.

7. Anti-tuberculosis drug resistance in the worl: Fourth global report. The WHO/IUATLD Global Project on Anti-Tuberculosis Drug Resistance Surveillance 2002-2007. Geneva: World Health Organization; 2008. Available from; http://www.who.int/tb/ publications/2008/drs_report4_26febo8.pdf

8. Guidelines for the programmatic management of drug-resistant tuberculosis. Emergency Update 2008. Geneva: World Health Organization; 2008. Available from: http://whqlibdoc.who.int/ publications/2008/9789241547581_eng.pdf

9. Gandhi NR, Moll A, Sturm AW, Pawinski R, Govender T, Lalloo $\mathrm{U}$, et al. Extensively drug-resistant tuberculosis as a cause of death in patients co-infected with tuberculosis and HIV in a rural area of South Africa. Lancet. 2006;368(9547):1575-80.
10. Shah NS, Wright A, Bai GH, Barrera L, Boulahbal F, MartínCasabona N, et al. Worldwide emergence of extensively drugresistant tuberculosis. Emerg Infect Dis. 2007;13(3):380-7.

11. Manissero D, Fernandez de la Hoz K. Extensive drug-resistant TB: a threat for Europe? Euro Surveill. 2006;11(39). pii=3056. Available from: http://www.eurosurveillance.org/ViewArticle. aspx?Articleld $=3056$

12. Hollo V, Amato-Gauci A, Ködmön C, Manissero D. Tuberculosis in the EU and EEA/EFTA countries - what is the latest data telling us?. Euro Surveill. 2009;14(11). pii=19151. Available from: http://www.eurosurveillance.org/ViewArticle. aspx?Articleld $=19151$

13. Schwoebel V, Lambregts van Weezenbeeck CS, Moro ML, Drobniewski F, Hoffner SE, Raviglione MC, et al. Standardisation of antituberculosis drug resistance surveillance in Europe. Recommendations of a World Health Organization (WHO) and International Union against Tuberculosis and Lung Disease (IUATLD) Working Group. Eur Respir J. 2000;16(2):364-71.

14. Extensively drug-resistant tuberculosis (XDR TB): recommendations for prevention and control. Wkly Epidemiol Rec. 2006;81(45):430-32.

15. Plan to Stop TB in 18 High-priority Countries in the WHO European Region, 2007-2015. Copenhagen: World Health Organization Regional Office for Europe; 2007. Available from: http://www.euro.who.int/document/E91049.pdf 